\title{
Estimating the sensitivity of forest soils to acid deposition in the Athabasca Oil Sands Region, Alberta
}

\author{
Colin J. WHITFIELD*, Julian AHERNE, Shaun A. WATMOUGH and Marjorie McDONALD \\ Environmental and Resource Studies, Trent University, 1600 West Bank Drive, Peterborough, ON K9J 7B8, Canada \\ *e-mail corresponding author: cwhitfield@trentu.ca
}

\begin{abstract}
The Athabasca Oil Sands Region of northern Alberta is home to the largest source of S emissions in Canada, and some of the surrounding upland forests are located on acid-sensitive soils. The relative sensitivity of these ecosystems to acidic deposition is largely dependent upon the mineral weathering rate. Weathering rates were evaluated across a range of soils $(n=43)$ typical of the region using a soil texture approximation (STA) and the PROFILE model. The STA was recalibrated for use in the region, and the weathering rates calculated with this method were used to calculate steady-state critical loads of acidity at 333 sites using the Simple Mass Balance (SMB) Model and a critical chemical criterion for molar base cation $\left(\mathrm{Ca}^{2+}, \mathrm{Mg}^{2+}, \mathrm{K}^{+}\right)$to aluminium ratio of 10 . Soils are dominated by quartz, with small quantities of slowly weatherable minerals, and consequently weathering rates are among the lowest in Canada (median $=11.5 \mathrm{meq}^{-2} \mathrm{y}^{-1}$ ), resulting in very low critical loads. Atmospheric acid $(S$ and $N)$ deposition varies considerably across the region, but in general is much lower than impacted areas of central Canada. Under conditions of complete $N$ retention, 34\% of the sites receive acid deposition in excess of their critical load; if all $N$ deposition is leached, $62 \%$ of the sites are currently exceeded. Acid-sensitive soils in the region are at risk of acidifying due to pressures from industrialization associated with extraction of fossil fuels.
\end{abstract}

Key words: acid-sensitive, critical loads, PROFILE, weathering, Canada

\section{INTRODUCTION}

Large expanses of northern Alberta, Canada have been classified as being acid-sensitive owing to the presence of poorly weatherable mineral soils (Shewchuk 1982; Holowaychuk \& Fessenden 1987). Much of this area is underlain by fossil fuel in the form of bitumen bound to sandy mineral soils that collectively forms the world's second largest recoverable oil deposit. The aptly named Athabasca Oil Sands Region (AOSR), centred on the town of Fort McMurray, has been subject to largescale industrial development in recent years (strip mining and in-situ extraction techniques). As a consequence, atmospheric emissions of acid precursors, sulphur dioxide $\left(\mathrm{SO}_{2}\right)$ and nitrogen oxides $\left(\mathrm{NO}_{\mathrm{x}}\right)$ have risen dramatically. Nationally, emissions of these compounds are highest in the province of Alberta (Environment Canada 2004) largely due to contributions from the oil sands industry (Legge 1990; Canadian Council of Ministers of the Environment 2006). Production is anticipated to triple over the next decade (Timilsina et al. 2005), and consequently it is important to assess the potential for acidification impacts resulting from elevated acid deposition levels.

The (steady-state) critical load $(C L)$, defined as the highest load of acidic deposition below which damage to specified sensitive biological components of the ecosystem will not occur over the long-term (Nilsson \& Grennfelt 1988), is a widely used approach for assessing ecosystem sensitivity. Critical loads have become the de facto approach for assessing the regional impact of acid deposition in Europe and are becoming increasingly important in North America; $C L S$ and critical load exceedance have been calculated for forest soils (Hettelingh et al. 2001, 2007) and surface waters (Henriksen et al. 1992) across most of Europe and also for regions in Asia (Zhao et al. 2007) and North America, including central and eastern Canada (Environment Canada 2004; Ouimet et al. 2006).

Over the past two decades, several studies have assessed regional soil sensitivity and CLs of acidity in Alberta (Turchenek et al. 1987; Alberta Environment 1990; Foster et al. 2001; Aherne 2008); however, soil characteristics for model input are often based on coarse scale soil maps which have been highlighted as a source of uncertainty. A key determinant of a $C L$ is the mineral weathering rate; it represents the only long-term supply of base cations (calcium: $\mathrm{Ca}^{2+}$; magnesium: $\mathrm{Mg}^{2+}$; sodium: $\mathrm{Na}^{+}$; and potassium: $\mathrm{K}^{+}$) to terrestrial ecosystems (other than atmospheric deposition) (Wilson 1986). A number of methods are available for estimating weathering rates (e.g., Zirconium depletion: Kirkwood \& Nesbitt (1991), Soil texture approximation (STA): UBA (2004), PROFILE model: Warfinge \& Sverdrup (1992)); however, few comparisons of the methods have been carried out in Canada. The empirical STA method was compared to the process-oriented PROFILE model for soils in Nova Scotia, and despite differences in data requirements their total weathering rate estimates demonstrated close agreement (Whitfield 
et al. 2006). A soil texture approximation based on percent clay content (Ouimet 2005) has been widely used in Canada to generate regional assessments of acid sensitivity owing to its minimal data requirements.

In order to apply critical loads on a regional basis in the AOSR it is important that a robust and reliable method with modest data requirements is available to generate weathering rate estimates. In the current study, the STA and PROFILE methods were applied to 43 sites across the AOSR where detailed soil data (including mineralogy) were collected. Secondly, a recalibrated STA method was used to calculate $C L s$ for these sites and a larger dataset $(n=290)$ collated from regional soil surveys. The central objective of this work was to assess the potential for acidification of upland forest soils under current levels of sulphur $(\mathrm{S})$ and nitrogen $(\mathrm{N})$ deposition.

\section{METHODS}

\subsection{Study Area}

The AOSR, lies largely in the Boreal Plains ecozone (Environment Canada 1996), but the northern reaches occupy the Boreal Shield ecozone near lake Athabasca. The region experiences a continental climate with warm summers and cold winters. The terrestrial landscape is composed largely of muskeg peatlands where black spruce (Picea mariana) are common, but mineral soil uplands featuring jack pine (Pinus banksiana) and trembling aspen (Populus tremuloides) are also a prominent landscape feature. Much of this upland terrain is acid-sensitive, typically composed of eluviated dystric brunisols (Agriculture and Agri-Food Canada 1998) characterized as having low exchangeable base cations and low cation exchange capacity (Holowaychuk and Fessenden 1987, Turchenek et al. 1987). Mineral soils included in this analysis are distributed across an area of approximately $120,000 \mathrm{~km}^{2}$.

\subsection{Data collection}

Soil samples for comparison of STA and PROFILE weathering rate estimation methods were collected at 43 plots across the region during the period 2005-2007, with the sites located mainly on acid-sensitive soils, but not necessarily restricted to them. Composite samples were collected from the forest floor (LFH) (Agriculture and Agri-Food Canada 1998) and mineral horizons of a single soil pit in order to detail physicochemical parameters in the rooting zone for each site. Briefly, depths of each horizon were measured in the field, samples were transported to the laboratory, air dried and sieved to $2.0 \mathrm{~mm}$ prior to analysis. Mineralogical analysis was conducted by X-ray diffraction using a Siemens (Bruker) D5000 Bragg-Brentano diffractometer. Particle size analysis to determine the proportions of sand, silt and clay in each soil horizon was undertaken using a
Horiba Partica LA-950 and used to calculate soil surface area (SA) following Hodson et al. (1998):

$$
S A=(3 \cdot \text { sand }+24 \cdot \text { silt }+47 \cdot \text { clay }) \cdot B D
$$

where $S A$, expressed as $\mathrm{m}^{2} \mathrm{~m}^{-3}$, is calculated from the percentage of sand, silt and clay, and the bulk density $\left(B D: \mathrm{kg} \mathrm{m}^{-3}\right)$ of the soil. Bulk density was calculated from loss on ignition (LOI) using a pedotransfer function (De Vos et al. 2005). Loss on ignition was measured following combustion at $450{ }^{\circ} \mathrm{C}$ for 12 hours in a muffle furnace. Default values for soil temperature (3.6 $\left.{ }^{\circ} \mathrm{C}\right)$ and moisture $\left(0.18 \mathrm{~m}^{2} \mathrm{~m}^{-3}\right)$ used at all study sites were estimated from annual averages at two monitoring stations in the region where these parameters were measured hourly over a two year period (using Campbell Scientific CR10X dataloggers connected to model 107 temperature probes and Delmhorst model 227 cylindrical soil moisture blocks).

In addition, data were collated from all available soil surveys (Siltanen et al. 1997; Alberta Sustainable Resource Development 2003; Cumulative Environmental Management Association 2005; Shaw et al. 2005; G. Brytus, pers. comm.), to calculate the $C L$ for forest soils using the Simple Mass Balance model (SMB: Sverdrup \& De Vries 1994). These soil surveys also focused on areas with acid-sensitive soils, and were not meant to be representative of all mineral soils in the region; however, some soils of lower sensitivity were also included. In total, sufficient information (horizon depths, BD and proportions of sand, silt and clay) from sampling for the current study and existing soil surveys was available for 333 sites.

Long-term average annual precipitation for each site was estimated using gridded $(35 \mathrm{~km} \times 35 \mathrm{~km})$ monthly climate normals (Mitchell et al. 2004). Runoff (soil percolation) was estimated from long-term precipitation minus actual evapotranspiration (Federer 1982). Total deposition of $\mathrm{Ca}^{2+}, \mathrm{Mg}^{2+}, \mathrm{S}$ and $\mathrm{N}$ at each site was interpolated from measurements (2005-2007) at 12 sites across the region. Total deposition of $\mathrm{Na}^{+}, \mathrm{K}^{+}$, and chloride was estimated from regional deposition maps at a resolution of $35 \mathrm{~km} \times 35 \mathrm{~km}$ (Vet \& Shaw 2004). Additional details describing derivation of deposition data are provided by Whitfield et al. (2009).

\subsection{Weathering rate estimation}

\subsubsection{PROFILE}

PROFILE (Warfvinge \& Sverdrup 1992) is a steadystate soil chemistry model that contains a sub-model for calculating mineral weathering rates of base cations using transition-state theory and independent geochemical properties of the soil system (e.g., soil moisture, temperature, surface area, $\mathrm{BD}$ and mineralogy). The weathering rate is largely influenced by soil type, climate and the abundance of weatherable minerals in the soil. The PROFILE model assumes that reactions lead- 
ing to mineral breakdown can only occur on exposed and wetted surfaces, and accordingly the model is sensitive to surface area and moisture content (Hodson et al. 1996). This process-oriented method has been tested extensively and is widely used, and is taken here as the 'correct' estimate of weathering in order to evaluate and recalibrate the clay-based STA method.

\subsubsection{Soil texture approximation}

The soil texture approximation method used here to estimate base cation weathering rates is a simple empirical pedotransfer function based on the percentage of clay in mineral soil and soil temperature. This claybased STA was calibrated to PROFILE using data from eastern Canada (Ouimet 2005):

$$
\begin{aligned}
& B C_{w}=\left(56.7 \cdot \text { clay }-0.32 \cdot \text { clay }^{2}\right) . \\
& \cdot d \cdot \exp \left(\frac{3600}{281}-\frac{3600}{T}\right)
\end{aligned}
$$

where clay is the percentage of soil less than $0.002 \mathrm{~mm}$, $d$ is the depth of soil (m) and $T$ is the average annual temperature of the soil (K). The method estimates the total base cation weathering rate (i.e. the sum of $\mathrm{Ca}^{2+}$, $\mathrm{Mg}^{2+}, \mathrm{Na}^{+}$and $\mathrm{K}^{+}$), while PROFILE estimates weathering rates for each cation. A step-wise multiple regression using clay and LOI as model parameters was used to recalibrate the STA for the study region.

\subsection{Critical loads}

The SMB assumes that the soil layer (typically representing the rooting zone) is homogeneous and that weathering rate is constant over time (independent of changes in climate and chemical conditions) and the $C L s$ are based on a specified critical chemical limit set to protect acid-sensitive biota. In this assessment all weathering rates and critical loads were calculated for an assumed mineral soil rooting depth of $0.5 \mathrm{~m}$ based on site observations. The principal of the SMB is that deposition of acid is set to balance the ecosystem sinks and sources of acidity in order to maintain the critical chemical limit. The critical load of acidity ( $\mathrm{S}$ and $\mathrm{N}$ ) can be calculated according to (ICP 2004):

$$
\begin{aligned}
& C L_{S+N}=B C_{d e p}+B C_{w}-B C_{u}+ \\
& +N_{i}+N_{u}+N_{d e n}-A N C_{\text {le(crit })}
\end{aligned}
$$

where $B C_{d e p}, B C_{w}$ and $B C_{u}$ refer to base cation deposition, weathering and net vegetative uptake (harvesting removal) and $N_{i}, N_{u}$ and $N_{d e n}$ correspond to nitrogen immobilization, vegetative uptake and denitrification, respectively (units are meq $\mathrm{m}^{-2} \mathrm{y}^{-1}$ ). In the current study harvesting removals were assumed negligible; $N_{u}$ and $B C_{u}$ were set to zero. Denitrification was also set to zero as nitrification dominates in well-drained soils (UBA 2004). The critical alkalinity leaching $\left(A N C_{\text {le(crit) }}\right)$ is the maximum allowable acid neutralizing capacity that can be leached from the rooting zone and is calculated as (ICP 2004):

$$
\begin{aligned}
& A N C_{\text {le(crit) }}=-Q^{\frac{2}{3}} \cdot\left(1.5 \cdot\left(\frac{B c_{w}+B c_{d e p}-B c_{u}}{(B c: A l)_{c r i t} \cdot K_{\text {Gibb }}}\right)\right)^{\frac{1}{3}}- \\
& -1.5 \cdot\left(\frac{B c_{w}+B c_{d e p}-B c_{u}}{(B c: A l)_{c r i t}}\right)
\end{aligned}
$$

While the choice of critical chemical limit is controversial (Skeffington 2006), in the current study a critical base cation to aluminium molar ratio $\left((B c: A l)_{c r i t}\right)$ of 10 , used to protect base saturation of soils in eastern Canada (Ouimet et al. 2006), was chosen for use. A default gibbsite dissolution constant $\left(K_{G i b b}\right)$ of $3000 \mathrm{~m}^{6} \mathrm{eq}^{-2}$ $\left(\mathrm{p} K_{\text {Gibb }}=9.0\right.$ : UBA 2004) was used. The terms $B c_{w}$, $B c_{d e p}$ and $B c_{u}$ correspond to weathering, deposition and uptake of $\mathrm{Ca}^{2+}, \mathrm{Mg}^{2+}$, and $\mathrm{K}^{+}$only $\left(\mathrm{Na}^{+}\right.$excluded), while $Q$ represents the flux of water percolating through the soil. For $C L$ calculations based on the STA weathering rate; $B C_{w}$ rates were multiplied by 0.7 to estimate $B C_{w}$ (UBA 2004).

The potential for long-term $N_{i}$ is believed to be low in the AOSR (Calleson \& Gunderson 2005), but there is no consensus concerning the long-term sustainable immobilization rates in soils. Using a higher $N_{i}$ constant has the effect of immobilizing more nitrogen deposited on the soils, resulting in higher critical loads. Recommended values for $N_{i}$ can range from $0-35 \mathrm{meq} \mathrm{m}^{-2} \mathrm{y}^{-1}$ or even higher depending on soil type, soil age, disturbance level and vegetative species present (NEG-ECP 2001). To represent the range of plausible $C L s$, two scenarios were included in the current study. The first assumes complete $\mathrm{N}$ retention $\left(N_{i}\right.$ is set equal to $\mathrm{N}$ deposition: $\max =63$ meq $\mathrm{m}^{-2} \mathrm{y}^{-1}$ ), which is consistent with current observations at sites receiving moderate levels of $\mathrm{N}$ deposition in the region (D.L. Laxton, unpublished data). The second assumes a less optimistic (worst-case) scenario, wherein all $\mathrm{N}$ deposited to the forests is leached $\left(N_{i}=0\right)$. Critical load exceedance of $\mathrm{S}$ and $\mathrm{N}\left(\operatorname{Exc}_{S+N}\right)$ (i.e. acidic deposition $\left.>C L\right)$ was calculated as:

$$
E x c_{S+N}=S_{d e p}+N_{d e p}-C L_{S+N}
$$

\section{RESULTS AND DISCUSSION}

\subsection{Evaluation of the soil texture approximation}

Weathering rates estimated using the clay-based STA and PROFILE methods were low at the majority of the 43 sites where detailed soil data were available. Soil texture approximation weathering rates ranged from 0 $72 \mathrm{meq} \mathrm{m}^{-2} \mathrm{y}^{-1}$ while PROFILE estimates spanned a similar range (1.6-74 meq m $\left.\mathrm{m}^{-2} \mathrm{y}^{-1}\right)$. For soils with no measurable clay, the STA weathering rate estimate is zero; as silt and sand fractions contribute relatively small amounts of weathering, this approximation can underestimate the actual weathering rate. The majority of the sites had estimated weathering rates below 20 meq $\mathrm{m}^{-2} \mathrm{y}^{-1}$; these are among the lowest weathering 

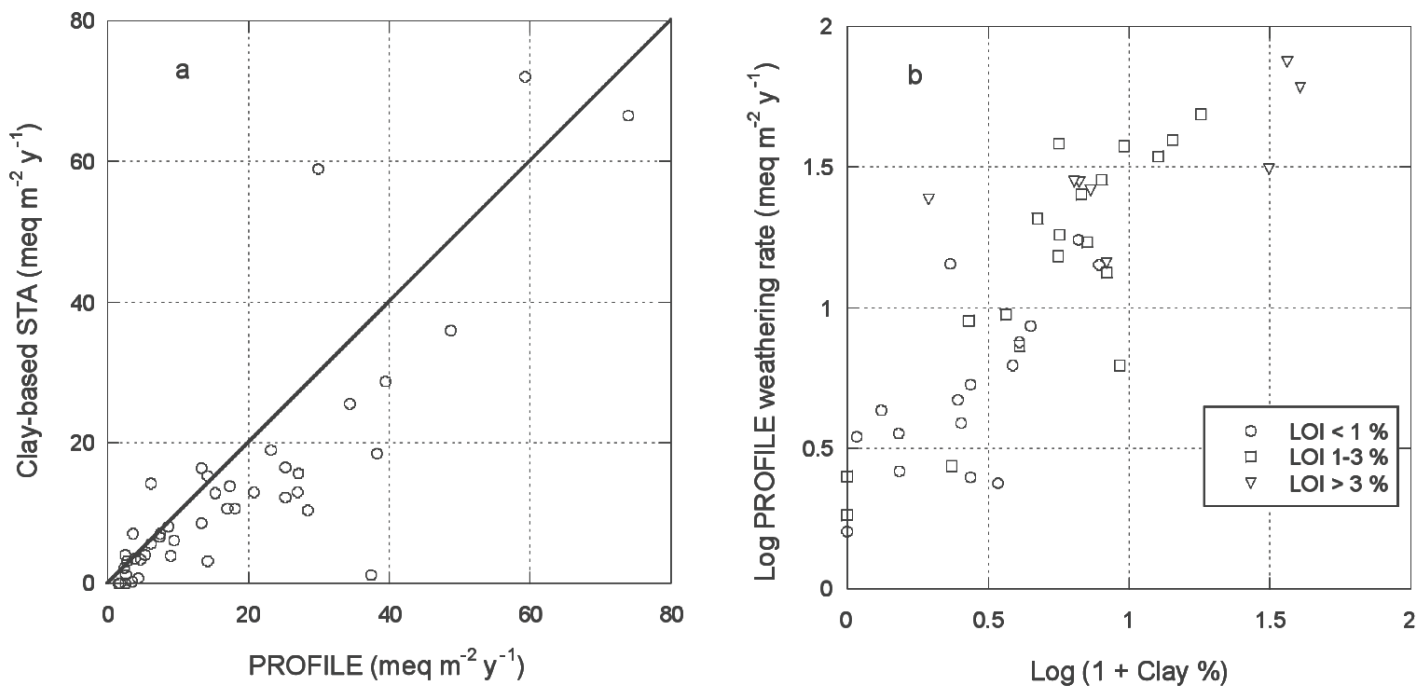

Fig. 1. Comparison of (a) weathering rate estimates using the clay-based soil texture approximation (STA) method and the PROFILE model $\left(r^{2}=0.70\right)$, with the one to one line shown, and (b) the PROFILE estimated weathering rate against the clay content of the soil, grouped by loss on ignition (LOI) of the soil.

rates in Canada, where reported rates range from 3-13 meq $\mathrm{m}^{-2} \mathrm{y}^{-1}$ in Nova Scotia (Whitfield et al. 2006), 19$131 \mathrm{meq} \mathrm{m}^{-2} \mathrm{y}^{-1}$ in Quebec (Courchesne et al. 2001; Ouimet \& Duchesne 2005), and 23-860 meq m $\mathrm{m}^{-2} \mathrm{y}^{-1}$ in Ontario (Arp et al. 1996; Watmough \& Dillon 2003). Evaluation of soil properties across these sites reveals a number of patterns that are indicative of low weathering rates. In general the proportion of mineral soils in the clay size fraction was very low; only 3 sites had more than $30 \%$ clay, while over half of the 43 sites had less than $5 \%$ clay. Given that weathering processes in PROFILE only occur on exposed and wetted mineral surface area, the dominance of larger size fractions limits the amount of weathering that will take place. Furthermore, the soils are dominated by unweatherable quartz, which averages $82 \%$ across the study sites, and only two sites have greater than $50 \%$ weatherable minerals. Of the weatherable minerals, plagioclase is the most common $($ mean $=6.1 \%)$ with muscovite $($ mean $=$ $4.5 \%$ ) and potassium-feldspar (mean $=3.7 \%$ ) also present at most sites. Magnesium-vermiculite and kaolinite were also commonly found in smaller amounts $(<2 \%)$, while biotite, iron-chlorite and calcite were rarely observed.

Comparison of the clay-based STA (see Eqn 2) and PROFILE estimated weathering rates revealed good agreement between methods $\left(r^{2}=0.70\right.$; Fig. 1a) with most points lying close to the one to one line. Evaluation of weathering rate estimates for the rooting zone in acid-sensitive regions of eastern Canada has also shown these methods to be comparable (Whitfield et al. 2006). PROFILE weathering is highly sensitive to surface area and bulk density, which of course are dependant on \% clay (see Eqn 1) and LOI (De Vos et al. 2005), and because of this data interdependence the estimates are expected to be correlated. In the current study, higher weathering rates are observed both where clay content is higher and where LOI is higher (Fig. 1b). Loss on ignition varies very little $(0-7 \%)$ and therefore $\mathrm{BD}$ is relatively constant across the study area; however LOI can be included in the recalibrated STA as an indicator of soil type. Average weathering rates are 6.4, 20 and 35 meq $\mathrm{m}^{-2} \mathrm{y}^{-1}$ for LOI classes $<1 \%, 1-3 \%$ and $>3 \%$, respectively. Recalibration of the STA to the current dataset using both clay and LOI improves the fit (1:1 relationship) with PROFILE generated estimated weathering rates $\left(r^{2}=0.78\right.$; Fig. 2$)$ :

$$
\begin{aligned}
& B C_{w}=-1.79+2.53 \cdot \text { clay }-0.03 \cdot \text { clay }^{2}+ \\
& +7.57 \cdot \text { LOI }-1.05 \cdot \text { LOI }^{2}
\end{aligned}
$$

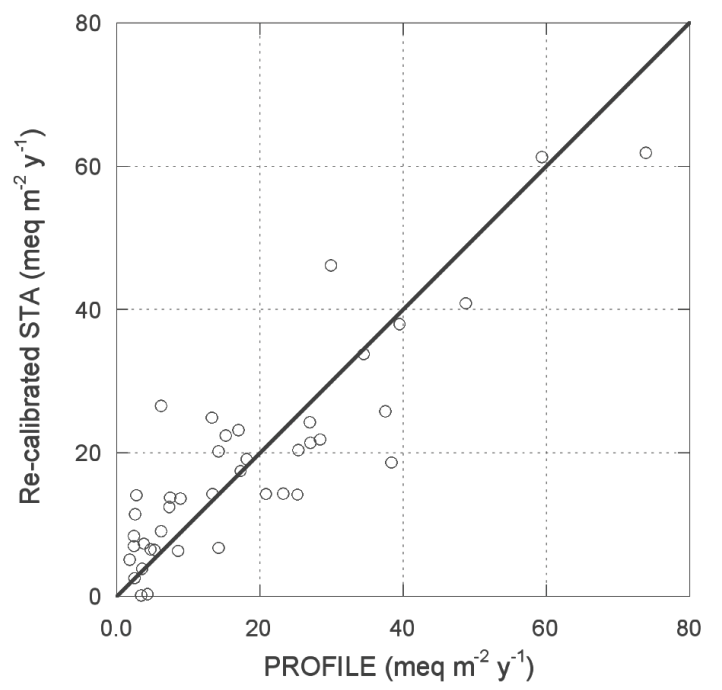

Fig. 2. Plot of the recalibrated soil texture approximation (STA) weathering rate (using \% clay and LOI; see Eqn 6) against the PROFILE calculated rate $\left(r^{2}=0.78\right)$. The solid line indicates perfect agreement between methods. 


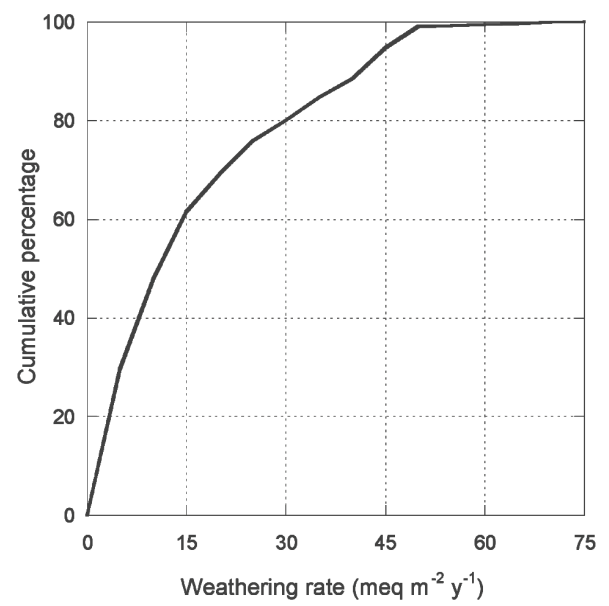

Fig. 3. Cumulative distribution of weathering rates for acidsensitive soils in the AOSR $(\mathrm{n}=333)$.
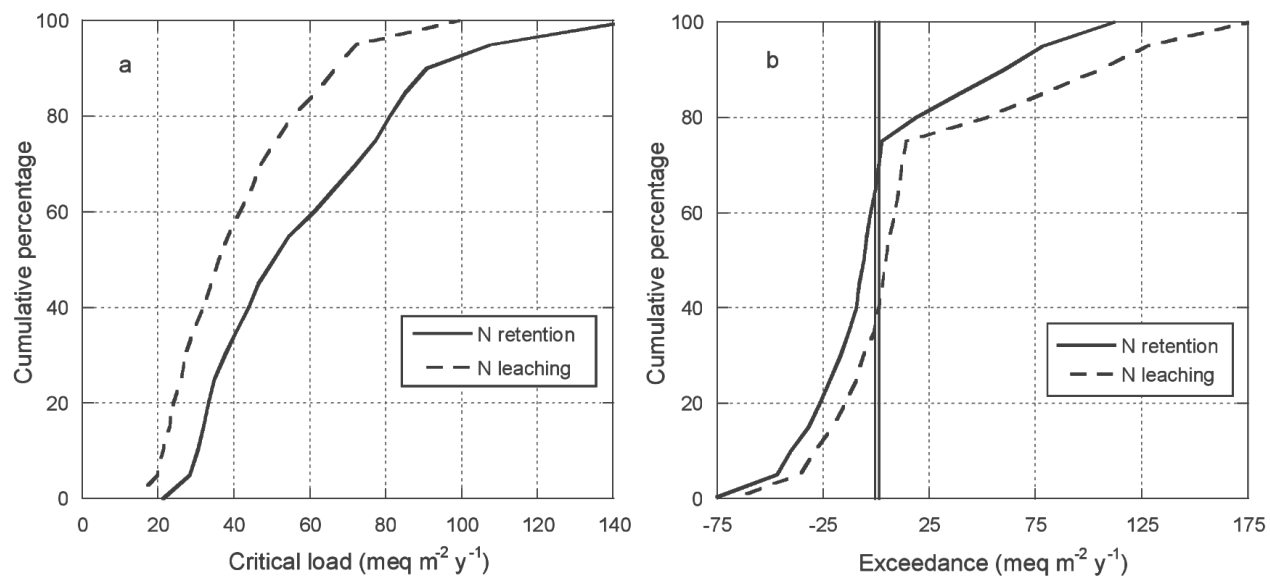

Fig. 4. Cumulative distributions of a) critical loads and b) exceedance under conditions of nitrogen (N) retention (solid line) and leaching (broken line). Double vertical line on panel b indicates non-exceeded (left) and exceeded (right) sections of each function.

In the current study, few sites had high weathering

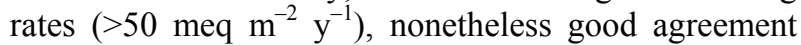
between weathering rate estimates suggests that the recalibrated STA method is suitable for estimating weathering rates within the range of clay $(0-40 \%)$ and LOI $(0-7 \%)$ observed at the 43 plots in the AOSR.

\subsection{Critical loads and exceedance}

Atmospheric deposition of acidity ( $\mathrm{S}$ and $\mathrm{N}$ ) in the Athabasca Oil Sands Region is quite variable, with the highest levels of deposition (155 and $63 \mathrm{meq} \mathrm{m}^{-2} \mathrm{y}^{-1}$ ) in the vicinity of the major emissions sources at the centre of the industrial activity. Deposition levels decrease with distance from the emissions sources, to lows of 8 (S) and $6(\mathrm{~N})$ meq $\mathrm{m}^{-2} \mathrm{y}^{-1}$ at several hundred kilometres from the core industrial area. Median deposition across the study sites was 24 meq m${ }^{-2} \mathrm{y}^{-1}$ for $\mathrm{S}$ and 11 meq m${ }^{-2}$ $\mathrm{y}^{-1}$ for $\mathrm{N}$. These levels are much lower than current and peak (1970s) acid deposition levels in eastern Canada where widespread impacts have been observed in sensitive regions (see Jeffries et al. 2003), but comparable to other areas of western Canada (e.g., Georgia Basin) facing pressures from acid deposition (D.P. Shaw, pers. comm.). Current deposition in the AOSR is based on limited observations, and continued and improved monitoring of acid deposition levels will help to reduce uncertainty for future modelling studies in the region, as the uncertainty surrounding acid deposition yields uncertainty in estimating critical load exceedances (Skeffington 2006).

The regional soil survey data were filtered to include only sites with clay content $(<40 \%)$ and LOI $(<7 \%)$ data in the range of the 43 sites used to recalibrate the STA; approximately $95 \%$ of the soil points $(\mathrm{n}=290)$ met these criteria. Accordingly, because this analysis focuses on the most acid-sensitive sites, their weathering rate estimates were very low (Fig. 3). The majority $(60 \%)$ of the sites have weathering rates below $15 \mathrm{meq}$ $\mathrm{m}^{-2} \mathrm{y}^{-1}$. In concert, critical loads of acidity for these sites were also very low (Fig. 4), owing to the large influence of weathering rate on the $C L$ calculation. Under conditions of complete $\mathrm{N}$ retention, critical loads 


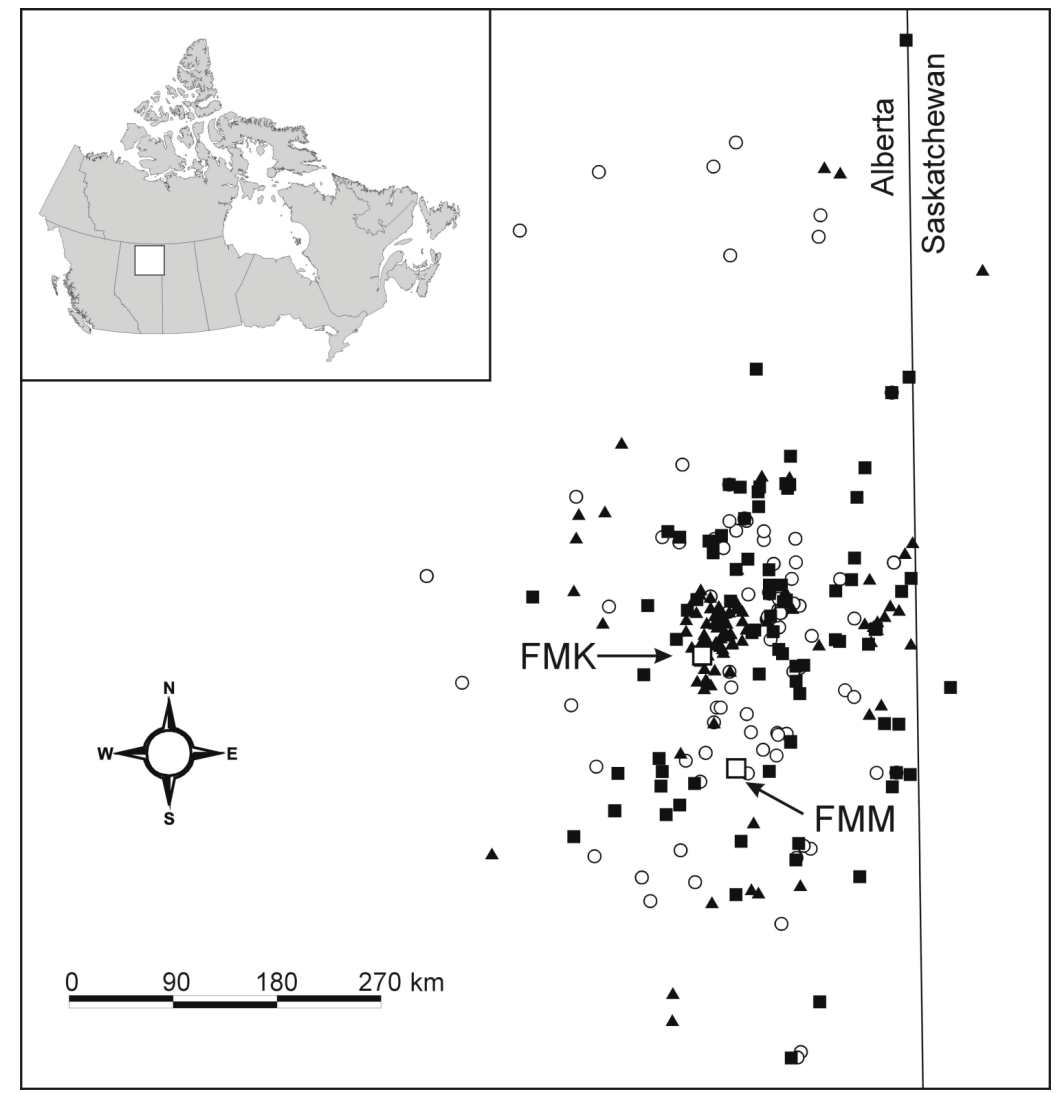

Fig. 5. Location of the study area (inset) in northern Alberta, Canada. The location of each forest soil plot $(\mathrm{n}=333)$ is displayed according to whether critical loads are: not exceeded (open circles), exceeded under $\mathrm{N}$ leaching conditions (filled squares), or exceeded under conditions of $\mathrm{N}$ retention (filled triangles). The towns of Fort McMurray (FMM) and Fort McKay (FMK) are also indicated (large open squares).

averaged $58 \mathrm{meq} \mathrm{m}^{-2} \mathrm{y}^{-1}$ (min: $21 \mathrm{meq} \mathrm{m}^{-2} \mathrm{y}^{-1}$, max: $144 \mathrm{meq} \mathrm{m}^{-2} \mathrm{y}^{-1}$ ). Under the assumption that all atmospherically deposited $\mathrm{N}$ is leached from the soil rooting zone, critical loads were lower, averaging only $40 \mathrm{meq}$ $\mathrm{m}^{-2} \mathrm{y}^{-1}$ (min: $14 \mathrm{meq} \mathrm{m}^{-2} \mathrm{y}^{-1}$, max: 99 meq $\mathrm{m}^{-2} \mathrm{y}^{-1}$ ). Corresponding exceedance calculations indicate that a large number of sites receive atmospheric deposition in excess of the critical load at present (2006) deposition levels (Fig. 4); 34\% under $\mathrm{N}$ retention, and 62\% under $\mathrm{N}$ leaching conditions. This result represents a large increase in the proportion of sites exceeded relative to the work of Aherne (2008) who reported exceedance for only $11 \%$ of the mapping units where CLs were calculated. The methodologies were only partially consistent between the two studies, but the current study incorporates the most recent atmospheric deposition data and uses a regionally calibrated weathering rate estimate in the $C L$ calculations. This represents the most robust assessment of CLs for soils performed in the study region to date. Given that $C L s$ are exceeded at a considerable proportion of sites even under the assumption of $\mathrm{N}$ retention, there is cause for concern, as the acidification impacts in the region have the potential to be widespread (Fig. 5), particularly as emissions of acid precursors are anticipated to increase in the future. Because a point-based approach has been used in the current study, estimates of the total area expected to be impacted by acid deposition can not be derived at present. Future work that moves from a point-based to a polygon-based approach would aid in identifying the areas of forest at greatest risk of acidifying.

There are a range of $(B c: A l)_{\text {crit }}$ values recommended for use in $C L$ calculations, and this can have an important impact on the level of CLs. It should be cautioned that the selection of the molar $(B c: A l)_{\text {crit }}$ ratio used in this study was based on work from eastern Canada (Arp et al. 1996). For trembling aspen a $(B c: A l)_{\text {crit }}$ of 6 has been reported, while for jack pine, 1.5 has been linked to reduced growth (see Sverdrup \& Warfvinge 1993). A $(B c: A l)_{\text {crit }}$ of 1 is the most commonly used value in European $C L$ assessments. As the ratio used here is among the most protective, it should provide a precautionary representation of $C L s$ for the region; however, forest harvesting is an active industry in the region and would exacerbate the situation as presented here owing to the removal (uptake) of base cations from these systems. Further work that links the molar $(B c: A l)_{\text {crit }}$ to potential biological responses of sensitive vegetation in the AOSR would be beneficial to future modelling studies.

In contrast to Europe, where the $C L$ concept has been entrenched in policy (e.g., Gothenburg protocol), 
the emissions management framework for the AOSR does not incorporate $C L s$ (or exceedance). Emissions management decisions are instead based on the timeframes within which specified critical chemical conditions are anticipated to be met. Critical loads represent a long-term condition of the system at steady-state, and do not identify when a specific chemical condition will be reached. As such, dynamic models are needed to support the emissions management framework. Whitfield et al. (2010, this issue) describe such an approach for applying the MAGIC model (Cosby et al. 1985) at the regional scale in the AOSR. Given the number of sites across the region where weathering rates are very low, and the potential for critical loads of acidity to be exceeded, either at present or in the future under elevated acid deposition, there is a need to expand dynamic modelling studies to assess the temporal response of acid-sensitive soils in the region.

\section{ACKNOWLEDGEMENTS}

Financial support for this study was provided by the Cumulative Environmental Management Association (CEMA) and a Natural Sciences and Engineering Research Council (NSERC) Collaborative Research and Development Grant awarded to JA and SAW. This research was undertaken, in part, thanks to funding from the Canada Research Chairs Program and an NSERC Discovery grant. The authors thank M. Posch for providing interpolated precipitation and runoff data and $\mathrm{A}$. Adkinson, D. Laxton and T. Seabert for assistance with sample collection.

\section{REFERENCES}

Agriculture and Agri-Food Canada. 1998. The Canadian system of soil classification. $3^{\text {rd }}$ edition. AAFC, Ottawa, Canada.

Aherne, J. 2008. Calculating critical loads of acid deposition for forest soils in Alberta: critical load, exceedance and limitations. Final Report, Environmental and Resource Studies, Trent University, Peterborough, Ontario: $14 \mathrm{pp}$.

Alberta Environment. 1990. A review of approaches for setting acidic deposition limits in Alberta. Alberta Environmental Protection, Report No. 0132. Edmonton, Alberta.

Alberta Sustainable Resource Development. 2003. Ecological land survey site description manual. $2^{\text {nd }}$ edition. Alberta Environment Publication No.: T/036: 112 pp.

Arp, P.A., T. Oja \& M. Marsh. 1996. Calculating critical S and $\mathrm{N}$ loads and current exceedances for upland forests in southern Ontario, Canada. Can. J. For. Res., 26: 696-709.

Callesen, I. \& P. Gunderson. 2005. Nitrogen sinks in boreal ecosystems. Report \#2003-0039 prepared for the Cumulative Environmental Management Association, Wood Buffalo Region. Danish Centre for Forest, Landscape and Planning, Royal Veterinarian and Agricultural University (KVL). Copenhagen, Denmark: 73 pp.

Canadian Council of Ministers of the Environment. 2006. 2003 Annual progress report on the Canada-wide acid rain strategy for post-2000. Available at: www.ccme.ca/assets/ pdf/2003_acidrain_annprog_rpt_e1.0_web.pdf.

Cosby, B.J., G.M. Hornberger, J.N. Galloway \& R.F. Wright. 1985. Modeling the effects of acid deposition: assessment of a lumped parameter model of soil water and streamwater chemistry. Water Resour. Res., 21: 51-63.
Courchesne, F., G.A. Roy, P.M. Biron, B. Côté, J.W. Fyles \& W.H. Hendershot. 2001. Fluctuations of climatic conditions, elemental cycling and forest growth at the watershed scale. Environ. Monit. Assess., 67: 161-177.

Cumulative Environmental Management Association. 2005. Properties of sensitive soils. Prepared by AMEC Earth and Environmental AXYS Environmental Consultants Ltd and Alberta Research Council, Calgary, Alberta.

De Vos, B., M. Van Meirvenne, P. Quataert, J. Deckers \& B. Muys. 2005. Predictive quality of pedotransfer functions for estimating bulk density of forest soils. Soil Sci. Soc. Am. J., 69: 500-510.

Environment Canada. 1996. The state of Canada's environment directorate - 1996. Available at: www.ec.gc.ca/soerree/English/SOER/1996report/Doc/1-6-2-4-1.cfm

Environment Canada. 2004. 2004 Canadian acid deposition science assessment. Environment Canada, Meteorological Service of Canada, Downsview, ON, 2004. Available at: www.msc-smc.ec.gc.ca/saib/acid/assessment2004/summary /index e.html

Federer, C.A. 1982. Transpirational supply and demand: plant, soil and atmospheric effects evaluated by simulation. Water Resour. Res., 18: 355-362.

Foster, K.R., K. McDonald \& K. Eastlick. 2001. Development and application of critical, target, and monitoring loads for the management of acid deposition in Alberta, Canada. Water Air Soil Pollut. Focus, 1: 135-151.

Henriksen, A., J. Kämäri, M. Posch \& A. Wilander. 1992. Critical loads of acidity: Nordic surface waters. Ambio, 21: 356-363.

Hettelingh, J.-P., M. Posch \& P.A.M. De Smet. 2001. Multieffect critical loads used in multi-pollutant reduction agreements in Europe. Water Air Soil Pollut., 130: 11331138.

Hettelingh, J.-P., M. Posch, J. Slootweg, G.J. Reinds, T. Spranger \& L. Tarrason. 2007. Critical loads and dynamic modelling to assess European areas at risk of acidification and eutrophication. Water Air Soil Pollut. Focus, 7: 379-384.

Hodson, M.E., S.J. Langan \& M.J. Wilson. 1996. A sensitivity analysis of the PROFILE model in relation to the calculation of soil weathering rates. Appl. Geochem., 11: 835-844.

Hodson, M.E., S.J. Langan \& S. Meriau. 1998. Determination of mineral surface area in relation to the calculation of weathering rates. Geoderma, 83: 35-54.

Holowaychuk, N. \& R.J. Fessenden. 1987. Soil sensitivity to acid deposition and the potential of soils and geology in Alberta to reduce the acidity of acid inputs. Alberta Environment, Edmonton, Alberta.

ICP. 2004. International Cooperative Programme on Modelling and Mapping Critical Loads \& Levels and Air Pollution Effects, Risks and Trends: Chapter 5.3 M. Posch (Ed.). Laxenburg, Austria. Available at: icpmapping. org/cms/zeigeBereich/11/manual-english.html.

Jeffries, D.S., T.A. Clair, S. Couture, P.J. Dillon, J. Dupont, W. Keller, D.K. McNicol, M.A. Turner, R. Vet \& R. Weeber. 2003. Assessing the recovery of lakes in southeastern Canada from the effects of acidic deposition. Ambio, 32: 176-182.

Kirkwood, D.E. \& H.W. Nesbitt. 1991. Formation and evolution of soils from an acidified watershed: Plastic Lake, Ontario, Canada. Geochim. Cosmochim. Acta, 55: 12951308.

Legge, A.H. 1990. The present and potential effects of acidic and acidifying air pollutants on Alberta's Environment. Prepared for the acid deposition research program by the Kananaskis Centre of Environmental Research, University of Calgary, Calgary, Alberta.

Mitchell, T.D., T.R. Carter, P.D. Jones, M. Hulme \& M. New. 2004. A comprehensive set of high-resolution grids of monthly climate for Europe and the globe: the observed record (1901-2000) and 16 scenarios (2001-2100). Tyn- 
dall Centre for Climate Change Research Working Paper 55, Norwich, UK: 30pp.

NEG-ECP. 2001. Critical load of sulphur and nitrogen assessment and mapping protocol for upland forests. New England Governors and Eastern Canadian Premiers Environmental Task Group, Acid Rain Action Plan, Halifax, Canada.

Nilsson, J. \& P. Grennfelt (Eds). 1988. Critical loads for sulphur and nitrogen. Miljørapport 1988:15, NORD 1998:097, Nordic Council of Ministers, Copenhagen, Denmark: 418 pp.

Ouimet, R. 2005. Cartographie des charges critiques d'acidité des forêts: deuxième approximation, Government of Quebec, Ministry of Natural Resources and Wildlife, Internal Report no. 487: (in French).

Ouimet, R. \& L. Duchesne. 2005. Base cation mineral weathering and total release rates from soils in three calibrated forest watersheds on the Canadian Boreal Shield. Can. J. Soil Sci., 85: 245-260.

Ouimet, R., P.A. Arp, S.A. Watmough, J. Aherne \& I. Demerchent. 2006. Determining and mapping critical loads of acidity and exceedances for upland forest soils in eastern Canada. Water Air Soil Pollut., 172: 57-66.

Shaw, C.H., J.S. Bhatti \& K.J. Sabourin. 2005. An ecosystem carbon database for Canadian forests. Canadian Forest Service, Edmonton, Alberta.

Shewchuk, S.R. 1982. An acid deposition perspective for northeastern Alberta and northern Saskatchewan. Water Air Soil Pollut., 18: 413-419.

Siltanen, R.M., M.J. Apps, S.C. Zoltai, R.M. Mair \& W.L. Strong. 1997. A soil profile and organic carbon data base for Canadian forests and tundra mineral soils. Canadian Forest Service, Edmonton, Alberta.

Skeffington, R.A. 2006. Quantifying uncertainty in critical loads: (A) Literature review. Water Air Soil Pollut., 169: 3-24.

Sverdrup, H. \& W. De Vries. 1994. Calculating critical loads for acidity with the Simple Mass Balance Method. Water Air Soil Pollut., 72: 143-162.

Sverdrup, H. \& P. Warfinge. 1993. The effect of soil acidification on the growth of trees, grass and herbs as expressed by the $(\mathrm{Ca}+\mathrm{Mg}+\mathrm{K}) / \mathrm{Al}$ ratio. Reports in ecology and environmental engineering, Report 2, Lund University, Lund, Sweden.
Timilsina G.R., N. LeBlanc \& T. Walden. 2005. Economic impacts of Alberta's Oil Sands. Canadian Energy Research Institute, Calgary. Available at: www.ceri.ca/Publications/ documents/OilSandsReport-Final.PDF

Turchenek, L.W., S.A. Abboud, C.J. Tomas, R.J. Fessenden \& N. Holowaychuk. 1987. Effects of acid deposition on Alberta soils. Alberta Research Council Terrain Sciences Department, Calgary, Alberta.

UBA. 2004. Manual on methodologies and criteria for modelling and mapping critical loads \& levels and air pollution effects, risks and trends. Umweltbundesamt, Berlin.

Vet, R. \& M. Shaw. 2004. 1994-1998 average dry deposition velocities calculated using the MSC Air Quality Research Branch dry deposition model (RDM). Meteorological Service of Canada, Environment Canada, Toronto, Ontario.

Warfvinge, P. \& H. Sverdrup. 1992. Calculating critical loads of acid deposition with PROFILE - A steady-state soil chemistry model. Water Air Soil Pollut., 63: 119-143.

Watmough, S.A. \& P.J. Dillon. 2003. Base cation and nitrogen budgets for a mixed hardwood catchment in South-central Ontario. Ecosystems, 6: 675-693.

Whitfield, C.J., J. Aherne \& S.A. Watmough. 2009. Modelling soil acidification in the Athabasca Oil Sands Region, Alberta, Canada. Environ. Sci. Technol., 43: 5844-5850.

Whitfield, C.J., J. Aherne, B.J. Cosby \& S.A. Watmough. 2010. Modelling catchment response to acid deposition: a regional dual application of the MAGIC model to soils and lakes in the Athabasca Oil Sands Region, Alberta. $J$. Limnol., 69(Suppl. 1): 147-160. DOI: 10.3274/JL10-69S1-15.

Whitfield, C.J., S.A. Watmough, J. Aherne \& P.J. Dillon. 2006. A comparison of weathering rates for acid-sensitive catchments in Nova Scotia, Canada, and their impact on critical load calculations. Geoderma, 136: 899-911.

Wilson, M.J. 1986. Mineral weathering processes in podzolic soils on granitic materials and their implications for surface water acidification. J. Geol. Soc. London, 143: 691697.

Zhao, Y., L. Duan, T. Larssen, L. Hu \& J. Hao. 2007. Simultaneous assessment of deposition effects of base cations, sulphur, and nitrogen using an extended critical load function for acidification. Environ. Sci. Technol., 41: 18151820 . 